\title{
Diet's Cariogenicity and Healthfulness Index (DCHI) - A novel, comprehensive index for children
}

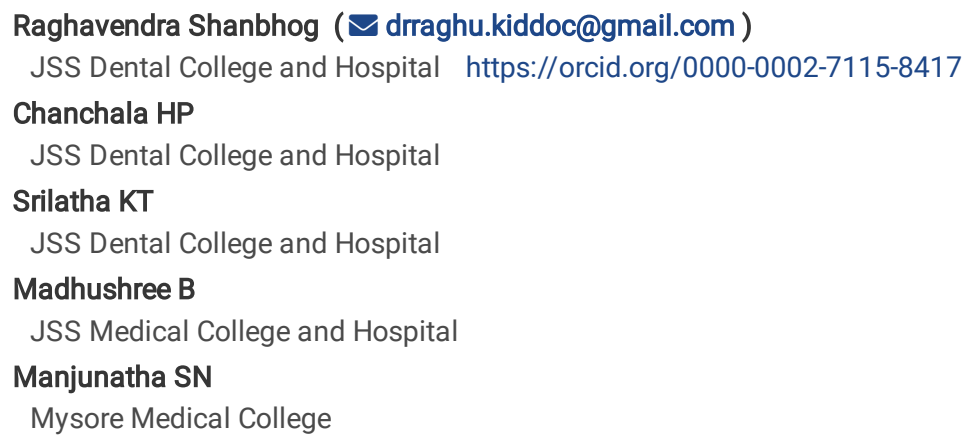

Research article

Keywords: Diet's Cariogenicity and Healthfullness Index, Children, Cariogenicity, Diet counseling, Dental caries and health

Posted Date: January 11th, 2021

DOl: https://doi.org/10.21203/rs.3.rs-45867/v2

License: (a) (i) This work is licensed under a Creative Commons Attribution 4.0 International License. Read Full License 


\section{Abstract}

Background:

A realistic and tailored dietary advice plays a vital role in Preventive Dentistry. An appropriate diet analysis forms the bases for a precise dietary advice. Analysis of diet for its cariogenicity is a complex process thus performing a meaningful diet analysis is a challenge in routine clinical practice. Currently, very few tools are available for researchers or clinicians to assess children's diet relating to caries risk. To the best of our knowledge an index that helps clinician to reduce composite diet diary information to a simple quantifiable interpretation is lacking. The current scientific paper presents a novel index that assesses the cariogenicity and healthfulness of child's diet objectively and guides the professional to achieve pragmatic diet modification in the prevention of dental caries.

Methods:

A team comprised of specialist from division of Pediatric dentistry, Community medicine and Diet and Nutrition along with a pilot parent-child population of number 50 were involved in initial structuring of Diet's Cariogenicity and Healthfulness Index. To obtain cut off values for cariogenicity of diet score a study was carried out with sample of 774 children correlating diet diary with caries status. A Receiver Operating Characteristic curve closest to the ideal of $100 \%$ sensitivity and $100 \%$ specificity was applied for statistical analysis.

Results:

Receiver Operating Characteristic curves plotted was 22.5 for diet scores for its cariogenicity. The sensitivity, specificity, and area under the curve of these cut-off values were 70 and 95 .

Conclusions:

The current scientific paper presents a novel Diet's Cariogenicity and Healthfulness Index that assesses the cariogenicity and healthfulness of child's diet objectively so as to guide the professional to achieve a pragmatic diet modification.

\section{Background}

Diet is the sum of food consumed by a person and a balanced diet is the one which provides all the nutrients in required amounts and proportions.[1] Dietary habits and selections play an important role in human health. Eating nutrient-dense foods and balancing energy maintains the health essential at all stages of life. Unbalanced consumption of food high in energy and low in essential nutrients contributes to chronic diseases including dental caries. [2]

Dental caries is a major global public health concern in the present day $[3,4]$ and it is prososed that the consumption of harmful fermentable carbohydrates is recognized to be an essential etiological cause particularly among children from the lowest socio-economic groups. [5-8]

India has a remarkable conglomeration of populations in terms of social, economic and cultural conditions. Food is an imperative part of Indian culture and plays a significant role in daily life. The diverse regions of the country have different dietary patterns. Indian cuisine varies from region to region, reflecting the ethnically diverse subcontinent. Rise in per capita income in India along with the growing mass media has impacted on the fast changing lifestyles, including dietary pattern. In the present day, snacking in between meals primarily containing unhealthy junk food with high carbohydrate content the caries experience in India was reported high in all the age groups and the percentage of individuals with caries experience increased as age advanced. The treatment needs of Indian children were also significantly high. So, tailored pragmatic diet modification aiming at reducing fermentable carbohydrate and improving healthfulness of diet forms a key in prevention of dental caries. [8, 9]

Analysis of diet for its cariogenicity is a complex process because fermentable sugars are often consumed in combinations. Also the properties of food like retention time, frequency, nutrient composition, and potentiality to stimulate saliva makes it further difficult to recognize its cariogenic potential. [911]However, currently few tools are available to assess children's diet related to caries risk and demonstrate how it can be successfully modified to reduce caries risk.

In 2002 American Academy of Pediatric Dentistry (AAPD) developed and advocated Caries risk assessment tool (CAT), which counts the frequency of inbetween-meal sugar attacks and bedtime exposure from bottles. [12] In 2004 dental health diet score [13] was discussed that gave points earned as a result of an adequate intake of food from each of the food groups essential for achieving and maintaining dental health. However this index does account for physical properties of food, also does not explain the guidelines for dietary modification. In 2009 University of lowa, The United States of America designed 'The Diet Assessment of Caries Risk tool' to help dental practitioners to identify dietary factors contributing to caries risk. [14] This collects information on frequency, amount, timing and manners of intake and supplemented with specific responses represented as low, moderate or high caries risk. However, it is subjective in nature. Further in 2013 cariogenicity index explained and concluded that because of the multifactorial nature of caries only liquid cariogenicity index has considerable potential in clinical settings. [15] In 2016 Moynihan P in contradiction to World Health Organization (WHO) issued guidelines (free sugars $\leq 10 \%$ ) recommended intake of $\leq 5 \%$ free sugars to protect dental health throughout life. [16]

So to the best of our knowledge an index that helps a clinician to reduce composite diet diary information to a simple quantifiable interpretation is lacking in literature. The aim of the present scientific paper was to explain the developed of a novel index for the assessment of the cariogenicity and 
healthfulness of child's diet objectively and guide the professional to achieve pragmatic diet modification and to deliver realistic advice for effective prevention of dental caries in children.

\section{The Diet's Cariogenicity and Healthfulness Index}

A team comprised of specialist from division of Pediatric dentistry, Community medicine and Diet and Nutrition were involved in development of DCHI.

DCHI index consist of 3 phases

Phase 1: Collection of Diet diary template

The child and parent duo were provided with a diet diary template (Figure 1) with verbal and written instructions to help them complete the diary along with examples of completed diaries. They were instructed to maintain a real-time record of what they drank and ate for 4 consecutive days including one weekend in the template provided to them. The diet diary template has a provision to record the time of consumption, alongside to describe the item consumed in detail (especially for the platter of multiple types), the amount in a household measuring systems and post-diet oral-cavity cleansing (rinsing). They were advised to provide details of each dietary intake such as the name of the food, brand names if any, additional items (sugar or sauces) as well as any medicine if consumed. Children were advised and encouraged to keep the diary with them all the time to instantly record any dietary intakes and avoid using atypical days that might be complicated by travel, illness, or unusual circumstances.

Phase 2 A: Analysis of diet diary template for assessment of cariogenicity

From the information collected through diet diary template, every intake of the child was analyzed by the clinician and scored as follows.

Step 1 (Figure 2)

1) Identify Food items consumed by the child at any given point of time, whether single type or a platter of multiple types?

a) If it is a Single type, check if it is a part of Miscellaneous from Table 2; if yes; assign score as per table 2. If no; proceed to step 2

b) If it is a platter of multiple types, check if it contains any food items belonging to Miscellaneous; if yes; give a single score of 3.5 for the entire platter of multiple types. If no; from the platter of multiple types identify major one food item and proceed to step 2

Examples for Single type: Biscuit, Pasta, Veg biryani

Examples for Platter of multiple types: Biscuit with milk, Pasta with potato chips, Lunch (2 Indian bread, 1 cup rice, 2 curries, 1 sweet, 1 vegetable)

Step 2 (Figure 3)

2) Identify the food, is it natural or processed $\star \star$ ?

a) For natural food items,

i) Identify which food group it belongs to?

Scoring: For food groups: Grain, Fruit or diary assign score 0.5

For food groups: Protein or vegetable assign score 0

ii) Identify whether food is in solid, semisolid or liquid state?

Scoring: For solid add score 1 , for semisolid add score 0.5 and for liquid add score 0

iii) Identify the nature of the food, sticky or non-sticky?

Scoring: If sticky add score 1 If non-sticky add score 0

b) For processed food items,

i) Based on its major ingredient identify which food group it belongs to?

Scoring: For food groups: Grain, Fruit or diary assign score 1.5

For food groups: Protein or vegetable assign score 0.5

ii) Identify whether external sugar has been added ?"

Scoring: If yes add score 1 , If no add score 0

Page 3/19 
iii) Identify whether food is in solid, semisolid or liquid state?

Scoring: For solid add score 1, for semisolid add score 0.5 and for liquid add score 0

iv) Identify the nature of the food, sticky or non-sticky?

Scoring: If sticky add score 1 If non-sticky add score 0

- **Processed food is defined as food that has had some sort of chemical or industrial treatment in order to cook it, preserve it, or improve its taste or appearance.

- \# Food item with added sugar or food belonging to miscellaneous food item consumed consecutively within 60 minutes interval, an addition of 1 for the later score.

- If child after every intake does not follow or is inconsistent in following the oral hygiene regime then add a score of 2 to per day diet score. If the child consumes food item with added sugar just before bed and skips oral hygiene regime an addition of score of 2 to per day diet score.

Based on the above criteria each intake of child was scored and added to obtain a cumulative score of four days.

The child's diet's cariogenicity score was computed as follows

Child's Diet's cariogenicity score $=4$ day cumulative score $/ 4$

Inference

A score of 23 and above was considered cariogenic, and a score below 23 was considered non cariogenic (based on Receiver Operating Characteristic curves results obtained from pilot work explained in result section)

Phase 2 B: Analysis of diet diary template for its Healthfulness (Figure 3)

Identify Food items consumed by the child at any given point of time, whether the single type or a platter multiple types?

a) If it is a Single type, check if it is a part of Miscellaneous (Table 1)

Scoring If yes, assign score 0 for five basic food groups.

If no Identity which one of the five basic food groups the intake belongs to and quantify the intake in terms of servings ${ }^{\star \star \star}$ and note under respective food group.

b) If it is a platter of multiple types, check if it contains any food items belonging to Miscellaneous?

Scoring For food items belonging to Miscellaneous assign score 0 for five basic food groups.

For the rest of the food, for each food items identify which one of the five basic food groups the intake belongs to and Quantify the intake in terms of servings.***

$\star \star \star$ - Convert house hold measurements written in diet diary in to serving using table 3

Based on the above criteria each intake of child was scored and the servings under each food group consumed by the child were computed for 4 consecutive days to obtain a cumulative four day score.

The child's diet's healthfulness score was computed as follows

Average servings score for each food group $=4$ day cumulative score for each food group $/ 4$

\section{Inference}

Calculated average servings for individual food group; if is equal or above the indicated serving by FGP (2002) for moderate calorie level (2200 caloriesIndicated for Children) [17] consider the child has consumed health full diet. Among the five food groups even if one food groups do not fulfill the indicated serving by FGP considered the diet as non-healthful.

Based on the inference of Phase $2 A$ and B, child's diet was classified into one of the following categories,

- Category I-Non cariogenic, Healthful

- Category II-Cariogenic, Healthful

- Category III- Non cariogenic, Non Healthful

- Category IV-Cariogenic, Non Healthful 
Illustration for Diet diary template analysis (Table 6)

Phase 3 -Diet counseling

Children categorized in Category I, need no counseling, instead, reinforcement for good diet practice and follow-up is needed. For children categorized in Category II, counseling by the dentist is advised; For Category III and IV counseling by a dietician in collaboration with the dentist is advised.

Guideline for diet counseling by dentist (from the cariogenic point of view)

Every child to be educated about the oral hygiene protocols to be followed using age-appropriate oral hygiene aids and to rinse after each food intake.

From diet diary received,

- Step1: Aim: To reduce miscellaneous food items to the maximum extent possible.

Clinician's task: Identify and mark all the dietary intakes by the child that are not associated with food groups but sweetened by the addition of sugars (miscellaneous food).eg: Chocolates, candy, pastry, chips and sweetened medicine

Correction: Child and parent duo should be made aware of the findings and advised to reduce the frequency of above-said intakes. They are asked to club the intake of miscellaneous food with either lunch or dinner and absolutely refrain these intakes just before bed. If possible sugared medicines changed to artificially sweetened ones. Whenever they consume miscellaneous food oral rinsing should be compulsory.

- Step 2: Aim: To reduce the intake of fermentable sugar as much as possible without disturbing intake of food group servings.

Clinician's task: Identify and mark all the dietary intakes by the child that are associated with basic five food groups but sweetened with the addition of sugars.

eg: milk with sugar, bread with jam, Chapati (Indian Bread) with ghee and sugar

Correction: Child and parent duo should be made aware of the effect of the addition of sugars and advised on a realistic type of correction. Each day one food item is considered for correction starting from the first meal of the day, Breakfast. The parents are advised to wean the added sugars without disturbing the main food group ingredient. Parents can substitute sugar, with honey or jaggery. Try to substitute sugar with no-sugar or permitted artificial sugar-based products without affecting the intake of the main course associated with food groups. This is expected to be followed for 4 weeks consecutively and advised on a recall follow up. Whenever they consume miscellaneous food oral rinsing should be compulsory

- Step 3: Aim: To improve the intake of Healthful diet.

Clinician's task: Identify and mark all the dietary intakes by the child that are associated with basic five food groups.

Correction: Child and parent duo consuming adequate quantity of Healthful diet should be appreciated and encouraged to consume diet of a varied selection that contains an adequate quantity of the nutrients.

Illustration depicted in Table 7shows post diet counseling modifications suggested for day 1 diet diary of child. Modification was done in the time of intake and emphasis on the oral hygiene instructions without omitting the miscellaneous diet of the child and converting the cariogenic diet score to noncariogenic score. The healthfulness of diet was also improved by the addition of varied food groups to the diet that was lacking.

Determination of Diet cariogenicity score cut-off value

\section{Methods}

\section{Ethical consideration}

The study plan was approved by the institutional ethical committee JSSAHER (JSS/DCH/Ethical/05-2017-18) and complied with the Declaration of Helsinki Ethical Principles for Medical Research. Permission to visit the schools and examine the children to collect data regarding Children's diet and dental caries was obtained from concerned Government \& the school authorities (A1/01/657/2018-19). Prior to participation, the parents were provided with detailed information about the study in regional language. Written consent was obtained from the participants.

\section{Subjects and study design}

To determine the cut-off values of diet score for predicting cariogenicity score of diet a cross-sectional study was carried out. The target population comprised of primary school children between 8 to 10 years of age residing in the Souther part of India. A stratified random sampling design was used where clusters consisted of primary schools stratified geographically across urban, suburban and rural areas of different states. The three stratas were proportional to the number of primary schools in each geographical area. Twenty five primary schools participated, representing the three strata. Access to the parents of the children in the target age group was achieved through face-to-face interaction during parent teacher meetings using bilingual study investigators. Role of parents is to emphasize the importance of keeping an honest record of dietary intake and guide the child to adhere to diet diary 
norms. Parents were provided with written information about the study and written informed consent was obtianed. Data was collected through oral examination and a structured diet diary format.

Sample size estimation

The sample size was determined using single population proportion formula $n=z^{2} p(1-p) / e 2$. The total sample size was calculated using the assumptions; proportion (p) of children with dental caries was estimated to be $70 \%$, confidence interval $95 \%(z=1.96)$, degree of precision (e) $5 \%$, non response rate of $20 \%$ to be 753 children $(n=753)$.

\section{Selection of study population}

A total of 1500 school children aged 8-10 years from twenty five primary stratified geographically across urban, suburban and rural areas of different states were screened clinically by two trained, calibrated examiners. Inter and intra-examiner reliability were measured and a kappa value of 0.8 was observed, which indicated good agreement. The dental caries of children was assessed using lifelong cumulative disease index the Decayed, Missing, Filled, (DMF) and decayed, extracted, filled (def). Based on WHO generated scale to classify caries severity (DMFT values between 0.0 and 1.1 were very low; 1.2-2.6 were low; 2.7-4.4 were moderate, 4.5-6.5 were high, and values exceeding 6.6 were very high) 1500 children were catogorized in to either low or high caries severity. From each catogory 450 children parent duo were randomly selected for diet evaluation. They were provided with 4 days diet diary template and asked to fill as explained above. Finally, sevenhundred and seventy four $(n=774)$ completed diet diary templates were recieved yielding a response rate of $86 \%$. The diet scores of each child were calculated as explained above.

\section{Statistical analysis}

The collected data was entered into the computer and checked for accuracy. Data management and analysis was conducted using SPSS ver. 24 (IBM SPSS Inc.). The Receiver Operating Characteristic curve analysis was performed to determine the optimal cut-off values for cariogenicity of diet scores in relevance to dental caries. The optimal cut-off values were obtained from the point on the Receiver Operating Characteristic curve closest to the ideal of $100 \%$ sensitivity and $100 \%$ specificity.

\section{Results}

Mean DMFT, deft values among low and high caries severity groups (Table 7). Mean caries prevelence in high caries severity group was $3.83 \pm 1.75$ and $0.25 \pm 0.43$ in low caries severity group. The mean difference between above groups was found to be statistically significant ( $p=0.001)$

To confirm the cut-off values for diet scores for their cariogenicity, a Receiver Operating Characteristic curves was plotted and area under the curve was calculated. As shown in, the Receiver Operating Characteristic curve optimal cut-off value was 22.5 for diet scores for its cariogenicity. The sensitivity, specificity, and area under the curve of these cut-off values were 70 and 95. (Figure 4 and Table $7 \& 8$ )

\section{Discussion}

Diet affects oral health both systemically and topically. Of both, the latter plays a key etiological role in the causation of dental caries. [18] Although, implementing lifestyle interventions that promote healthier eating has been recommended in many international oral health promotion guidelines and policy documents yet they are not being followed. To ensure effectiveness of these guidelines, the Interventional dietary advice needs certain modifications such as more realistic, comprehensive, and tailored to patient's needs. [19-21]

The choice of a population ranging between 8 to 10 years of age is important, because several children develop problems during this mixed dentition stage and child's ability to maintain diet diary is independent and thus requires only supervision from the parents

Primarily, Collection of typical eating habits forms a requisite for a convincing diet analysis. There have been retrospective and prospective 7 days, 3 days, and 24 hours diet diaries which have been discussed in literature with their advantages and disadvantages. Retrospective diet diary methods even though were considered ideal for older children with low literacy, is time-consuming. This leads to recall bias and may not be a representative of either usual eating habits or typical eating habits. [22-24] Prospective diet diaries with the elimination of memory bias were considered to be of higher validity due to their expected accuracy and representativeness of habitual dietary intake. [22, 25-28] Among all prospective diet diaries, 3-day diet diary emerged as the most reliable tool for dietary assessment However, in the recent past globalization has brought in many changes in the lifestyle of both parents and children. Now the weekend consists of 2 days being Saturday and Sunday unlike the past and as a result eating pattern of both parents and children varies on both the days from that of a routine. Thus the 3-day diet diary including weekend may not represent typical eating habits of the child. Therefore, the present study has proposed a 4-day prospective diet diary including at least one weekend that balances above said variability by including 2 working days with 2 holidays to record both the typical and atypical eating patterns. The present study diet diary was designed to collect information on the quantity and timing of food consumption and oral hygiene maintenance protocols of the child.

Over the years analysis of diet for appropriate diet counseling using complex diet diary has been a challenging issue. Studies have shown that dentist's analysis and judgments of diet diary information are influenced by their knowledge, values, and beliefs as well as available treatment. [29-33] To nullify this bias, in the present study a simple yet comprehensive analytical method based on the scientific background was developed and explained. 
The cariogenic potential of foods and beverages is determined by the potential of food to decrease the plaque pH which in turn depends upon the form of the food, fermentable carbohydrate and sugar including hidden sugars, retention time, and frequency of consumption, amount/quantity, in between meals, near bedtime, prolonged exposure, and sequence. The healthfulness of foods is determined by its nutrient composition. [34-39]

In the present study the first step of diet analysis was to investigate the form of the food whether it is natural or processed. Second and third steps will investigate regarding the food group to which the diet belonged to and information on addition of fermentable carbohydrate and external sugars. Later steps explores on the retention time based on information about the consistency of the food and the tackiness. Retentiveness of food is determined by its physical as well as chemical properties such as consistency, particle size, solubility, tackiness, cohesiveness and adhesiveness to the tooth surface. [4042] There is a variation in the clearance time for each and every individual food as they exhibit different retentive properties. [43] Literature reports higher rates of dental caries incidence to be associated with the consumption of refined carbohydrates in the retentive form (sticky). [44-48]

Frequency and amount of dietary sugar is another important aspect that determines cariogenicity of diet. Continuous exposure to refined carbohydrates prolongs the duration of a pH drop below the critical level and it also limits the buffering capacity of dental plaque and saliva by draining their reserves of minerals. [22, 49-52] Of frequency and amount of dietary sugar, targeting the frequency of sugar consumption rather than the amount may be a more realistic approach when addressing at an individual level. [51]So, in the present study dietary analysis will check frequency of food with added sugar consumed within 60 minutes interval between the meals, an additional score of 1 is assigned to diet score.

In the present indices, the baked and processed foods with the combination of sugar and starch (high-starch snacks) like deep fried fruits, vegetables, legumes, pulses, refined grains/ cereals, bakery items were categorized to miscellaneous group and assigned a higher score as in past literature it is found that high-starch snacks were associated with an increased cariogenicity. [ 46,52]

In the present indices, the food items like medicines in liquid or semi-solid forms with added sugar either sucrose or fructose or with a combination of fructose and sorbitol and carbonated drinks with artificial flavors produced a marked and long term drop in plaque $\mathrm{pH}$. The cariogenic potential of pediatric liquid medications is due to high concentration of fermentable carbohydrates and their acidogenicity. Various authors have expressed concern over the presence of fermentable carbohydrates in syrup medications and their adverse effects on the oral health of children on a long term. [53-55]

The decision of Healthfulness of diet for each food groups as consumed by the child was calculated based on average servings for individual food group and considered Healthful if it is equal or above the indicated serving by FGP for moderate calorie level (2002). [17] As per the FGP protocol a total calories 2,200 is right for children, as the amount of calories depends on how many calories you need and is inter dependent on the age, sex, size and how active the person/child is. [56-57]

Based on the inference availed post diet analysis the children were categorized as discussed previously. Children categorized in Category I, need no counseling, instead, reinforcement for good diet practice and follow-up is needed. For children categorized in Category II, counseling by the dentist is advised; For Category III and IV counseling by a dietician in collaboration with the dentist is advised.

In the previous literature, diet counseling was planned to primarily reduce the intake of fermentable sugar as much as possible without considering the nutritive value of the intake of food groups. Therefore, the diet counseling was carried out in a swift manner aiding in reducing the caries. In the present study, the diet consumed by the child is segregated in terms of the basic ingredient, method of preparation/processing, addition of external sugars etc to aid in the etiology of the dental caries. In this process the concentration is primarily focused only on the caries and its causation and absolute negligence towards the healthfulness of the diet. Therefore, in the category III and IV the diet would definitely consist of more cariogenic food and if these food items are advised to be weaned off or eliminated from the food plate as it would also hamper the nutritive component of the child's diet. Considering the healthfulness of the diet it is important to consume a balanced diet to facilitate the satisfactory growth and development. Another important aspect being the time constraints by the dentist to evaluate the details of the diet completely in cases of advanced diet counseling for children. The need for a dietitian has a vital role in systematic, feasible and achievable goal to make the child caries resistant without affecting the nutrition.

Indian food is different from rest of the world not only in taste but also in cooking methods. It reflects a perfect blend of various cultures and ages. Indian culture and food has been influenced by various civilizations and the present form cuisine differs across India's diverse regions as a result of variation in local culture, geographical location (proximity to sea, desert, or mountains), and economics. Most dishes feature meat or vegetables mixed with sauce and rice. Many Indians are vegetarian, so eating habits are often based on a diet that excludes meat. When meat is incorporated in dishes, it is most commonly in the form of chicken, lamb, and sometimes seafood, such as prawns. The present study cut of values for dental caries is based on food patterns of southern India.

Validity and reliability of the DCHI

An index should be valid, reliable, and pragmatic in its use and results should be easily reportable. Validating and testing the index's reliability are underway. Results will be presented in future.

\section{Limitations}

The cut off scores computed for cariogenicity of diet in present study are applicable only for the Indian population with food patterns of southern India and therefore it is suggested that further research from different regional and traditional locations based on their diet practices to be validated considering the same protocol to execute the cutoff values of diet score. Also cut off scores computed for cariogenicity of diet in present study is based 
on reported dietary feedback from children aged 8-10 years in terms of what they consumed, time and amounts. For other age groups in the same region the cut off scores for cariogenicity may differ. So further studies evaluating cut off scores for cariogenicity applicable to varied food patterns across globe and different age group of children is desired.

\section{Conclusion}

The current scientific paper presents a novel Diet's Cariogenicity and Healthfulness Index that assesses the cariogenicity and Healthfulness of child's diet objectively so as to guide the professional to achieve pragmatic diet modification. Since present index assesses the cariogenicity and Healthfulness of child's diet, objectively it becomes a functional tool during inter-professional teaching, research and practice in future.

\section{Abbreviations}

DCHI - Diet's Cariogenicity and Healthfulness Index

AAPD - American Academy of Pediatric Dentistry

CAT - Caries risk assessment tool

WHO - World Health Organization

FGP - Food Guide Pyramid

DMF - Decayed, Missing, Filled

def- decayed extracted filled

\section{Declarations}

\section{Ethics approval and consent to participate}

Written informed consent was obtained from parents and assent from children and the study protocol was approved by the institute's committee on human research. Full name of the ethics committee- JSS Dental College \& Hospital Institutional Ethics Committee Institute to which it belongs - JSS Dental College \& Hospital JSSAHER Mysuru Reference number - JSS/DCH/Ethical/PhD-05/2017-18

\section{Consent to publish}

Not applicable

\section{Availability of data and materials}

The datasets used and/or analyzed during the current study available from the corresponding author on reasonable request.

\section{Competing interests}

The authors declare no Competing interests

\section{Funding}

Nil

\section{Authors' Contributions}

Conception and design of the indices were done by R.S., C. HP., M.B., and M.SN Analyzing the data was done by M.B., M.SN. and KT.S. Writing the manuscript was done by R.S. and C. HP.

\section{Acknowledgement}

We would like to acknowledge Department of Diet and nutrition, JSSAHER, Mysuru for the valuable contribution in the development of indices

\section{References}

1. Skerrett PJ, Willett WC: Essentials of healthy eating a guide. J Midwifery Womens Health. 2010, 55 (6): $492-501$.

2. Willett WC, Koplan JP, Nugent R, et al.: Prevention of Chronic Disease by Means of Diet and Lifestyle Changes. 2nd edition. Washington (DC): The International Bank for Reconstruction and Development / The World Bank Chapter 44. Available from:

https://www.ncbi.nlm.nih.gov/books/NBK11795/ Co-published by Oxford University Press: New York. 2006 
3. Anil S, Anand PS: Early childhood caries: prevalence, risk factors, and prevention. Front Pediatr. 2017, 5:157.

4. Pitts N, Amaechi B, Niederman R, et al.: Global oral heath inequalities: dental caries task group - research agenda. Adv Dent Res.2011, $23: 211$ - 20.

5. Harris R, Nicoll AD, Adair PM, Pine CM:Risk factors for dental caries in young children: a systematic review of the literature. Community Dent Health.2004, 21: 71- 85.

6. Bonilla C, Brauer P, Royall D, Keller H, Hanning RM, DiCenso A :Use of electronic dietary assessment tools in primary care: an interdisciplinary perspective. BMC Med Inform Decis Mak. 2015, 15:14

7. Boyd LD, Dwyer JT: Guidelines for nutrition screening, assessment, and intervention in the dental office. J Dent Hyg. 1998,72 4: 31 - 43.

8. Levy TA, Raab CA: A study of the dietary counseling practices among Oregon dental hygienists. J Dent Hyg.1993, 67: 93;

9. World Health Organization (1996) Preparation and Use of Food-Based Dietary Guidelines. Report of a Joint FAO/WHO Consultation 1996 Nicosia, Cyprus.

10. Dietary Guidelines from Around the World Food and Nutrition Information Center. S. Department of Agriculture http://www.nal.usda.gov/fnic/dga/index.html

11. Rodrigues, CS, Sheiham A: 2000 The relationships between dietary guidelines, sugar intake and caries in primary teeth in low income Brazilian 3-yearolds: a longitudinal study. International Journal of Paediatric Dentistry. 2000, 10: 47-55.

12. Policy on use of a caries-risk assessment tool (CAT) for infants, children, and adolescents American Academy of Pediatric Dentistry Council on Clinical Affairs Reference Manual 31. 2002, 29-33.

13. Nizel papas: Nutrition in clinical dentistry, $3^{\text {rd }}$ edition WB saunders and company. $1989,277-307$

14. Marshall TA: Chairside diet assessment of caries risk. J Am Dent Assoc. 2009, 140 6:670-674.

15. Evans EW, Hayes C, Palmer CA, et al: Development of a pediatric cariogenicity index. J Public Health Dent. 2013, 73(3):179-186.

16. Moynihan P: Sugars and Dental Caries: Evidence for Setting a Recommended Threshold for Intake. 2016, 7(1):149-156.

17. "American Heritage Dictionary Entry: food pyramid". Ahdictionary.com. Archived from the original on 2014-10-25. Retrieved 2015-02-05.

18. Moynihan P, Petersen PE: Diet, nutrition and the prevention of dental diseases. Public Health Nutr. 2004, 7(1A):201-226.

19. Douglass JM, Clark MB: Integrating Oral Health Into Overall Health Care to Prevent Early Childhood Caries: Need, Evidence, and Solutions. Pediatr Dent. 2015, 37(3):266-274.

20. Watt RG:. From victim blaming to upstream action: tackling the social determinants of oral health inequalities. Community Dent Oral Epidemiol. 2007, 35(1):1-11.

21. Stevenson J, Tong A, Campbell KL, Craig JC, Lee VW: Perspectives of healthcare providers on the nutritional management of patients on haemodialysis in Australia: an interview study. BMJ Open. 2018, 8(3):e020023.

22. Rugg Gunn AJ, Nunn JH:Diet and dental erosion. Nutrition, diet and oral health, Ch. 4. Oxford: Oxford University Press Oxford; 1999.

23. Welch AA, McTaggart A, Mulligan AA et al: DINER (Data Into Nutrients for Epidemiological Research)-a new data-entry program for nutritional analysis in the EPIC-Norfolk cohort and the 7-day diary method. Public Health Nutr. 2001, 4:1253-1265

24. Wilkins EM. The Professional Dental Hygienist. In: Clinical Practice of the Dental Hygienist. 12th ed. Philadelphia: Wolters Kluwer Health: Lippincott Williams \& Wilkins. 2016,3-18.

25. Nizel AE, Papas AS: Nutrition in Clinical Dentistry.Philadelphia: W.B. Saunders Company 1989, 113-124.

26. Glanz, K, Sallis, JF, Saelens, BE et al: Healthy nutrition environments: concepts and measures. Am J Health Promot 2005, 19, 330-

27. Michie, S. \&Johnston, M: Theories and techniques of behaviour change: Developing a cumulative science of behaviour change. Health Psychol Rev. $2012,6,1-6$.

28. Wilkins EM \&Wyche, C. J: Clinical practice of the dental hygienist, Philadelphia, Pa. Lippincott Williams \& Wilkins. 2013, $496-516$.

29. Gafni A, Charles C, Whelan T: The physician-patient encounter: the physician as a perfect agent for the patient versus the informed treatment decision-making model. Soc Sci Me. 1998, 47(3):347-354.

30. White BA, Maupomé G: Clinical decision-making for dental caries management. J Dent Educ. 2001, 65(10):1121-1125.

31. McGlone P, Watt R, Sheiham A: Evidence-based dentistry: an overview of the challenges in changing professional practice. Br Dent J. 2001, 190:636639.

32. Khatami S, Macentee MI: Evolution of clinical reasoning in dental education. J Dent Educ. 2011, 75(3):321-328.

33. Harris R., Mosedale S., Garne J., Perkins E: What factors influence the use of contracts in the context of NHS dental practice - a systematic review of theory and logic model. Sci. Med 2014,108:54-59.

34. Riva Touger-Decker, Cor van Loveren: Sugars and dental caries, The American Journal of Clinical Nutrition. 2003, 78(4) 881S-892S.

35. Zero DT, Moynihan P, Lagström P, Birkhed D: The role of dietary control. In: fejerskov, o. \& kidd, e. A. M. (eds.) Dental caries : the disease and its clinical management. 2nd ed. Oxford :wiley-blackwell, 2008, 330-354.

36. Caldwell RC: The retention and clearance of food from the mouth. N. Y. Acad. Sci. 1968, 153, 64-70.

37. Caldwell RC: Physical properties of foods and their caries-producing potential. J Dent Res. 1970, 49(6):1293-1298. 
38. Luke GA, Gough H, Beeley JA, Geddes DA: Human salivary sugar clearance after sugar rinses and intake of foodstuffs. Caries Res. 1999, 33(2):123129.

39. Moynihan P, Petersen PE: Diet, nutrition and the prevention of dental diseases. Public Health Nutr. 2004, 7(1A):201-226.

40. Oliveby A, Weetman DA, Geddes DA, Lagerlöf F: The effect of salivary clearance of sucrose and fluoride on human dental plaque acidogenicity. Arch Oral Biol. 1990, 35(11):907-911.

41. Kashket S, Van Houte J, Lopez LR, Stocks S: Lack of correlation between food retention on the human dentition and consumer perception of food stickiness. J Dent Res. 1991,70(10):1314-1319.

42. Gustafsson BE, Quensel CE, Lanke LS, et al.: The Vipeholm dental caries study; the effect of different levels of carbohydrate intake on caries activity in 436 individuals observed for five years. Acta Odontol Scand. 1954, 11(3-4):232-264.

43. Kashket S, Zhang J, Van Houte J: Accumulation of fermentable sugars and metabolic acids in food particles that become entrapped on the dentition. J Dent Res. 1996, 75(11):1885-1891.

44. Marsh PD: Microbial ecology of dental plaque and its significance in health and disease. Adv Dent Res. 1994, 8(2):263-271.

45. Bradshaw DJ, Lynch RJ: Diet and the microbial aetiology of dental caries: new paradigms. Int Dent J. 2013, 63 Suppl 2:64-72.

46. Tahmassebi JF, Duggal MS, Malik-Kotru G, Curzon ME: Soft drinks and dental health: a review of the current literature. J Dent. $2006,34(1)$ : 2-11.

47. Paes Leme AF, Koo H, Bellato CM, Bedi G, Cury JA: The role of sucrose in cariogenic dental biofilm formation-new insight. J Dent Res. 2006, 85(10):878-887.

48. Moynihan PJ: Dietary advice in dental practice. Br Dent J. 2002, 193(10):563-568.

49. Moynihan P: Sugars and Dental Caries: Evidence for Setting a Recommended Threshold for Intake. Adv Nutr. 2016, 7(1):149-156.

50. Llena C, Forner L:. Dietary habits in a child population in relation to caries experience. Caries Res 2008, 42(5):387-393.

51. Hooley M, Skouteris H, Boganin C, Satur J, Kilpatrick N: Parental influence and the development of dental caries in children aged 0-6 years: a systematic review of the literature. J Dent. 2012, 40(11):873-885.

52. Geddes DA: Diet patterns and caries. Adv Dent Res. 1994, 8(2):221-224.

53. Kenny J, Somaya P: Sugar load of oral liquid medications on chronically ill children. J Cand Dent Ass. 1989, 55(1) : 43-46.

54. Rekola M: In vivo acid production from medicines in syrup form. Caries Res. 1989, 23(6):412-416.

55. Karjalainenm SM, Rekola, Stahlberg MR: Longterm effect of syrup medications for recurrent otitis media on the dental health of 6 to 8 year old children. Caries Res. 1992, 26: 310-314.

56. "Nutrition Plate Unveiled, Replacing Food Pyramid". The New York Times. 2 June 2011. Archived from the original on 3 June 2011. Retrieved 2 June 2011.

57. Gao X, Wilde PE, Lichtenstein AH, Tucker KL: The 2005 USDA Food Guide Pyramid is associated with more adequate nutrient intakes within energy constraints than the 1992 Pyramid. J Nutr. 2006, 136(5):1341-1346.

\section{Tables}

Table 1 Diet Diary Template

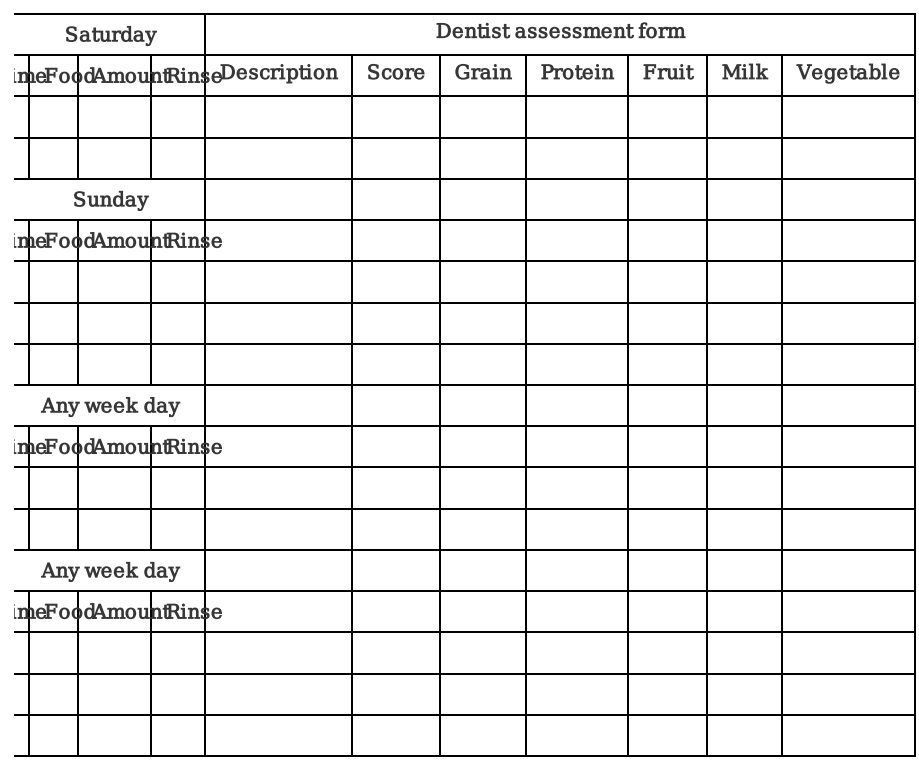

Amount should be expressed in Slices, pieces, tea spoon, table spoon, tumbler/Glass, cup and bowl, Scoop 
While scoring for following food items assign scores as follows

1. Medicines in liquid or semi-solid forms with added sugar - assign score 4.5

2. Direct intake of Honey, Sugarcane - assign score 2

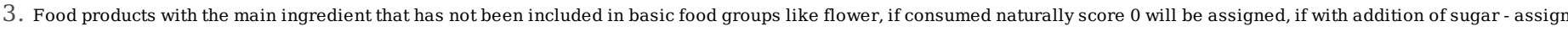
score 4 (eg-Gulkand)

4. Bakers' confectionery, Sweet condiments, sweets deserts, Sugary sweets- assign score 4.5

5. Carbonated drinks with artificial flavours and added sugar- assign score 4.5

6. Deep Fried Fruits, vegetables, Legumes, Pulses, refined grains/ cereals - assign score 4.5

Note:

1. Above mentioned miscellaneous food item if is part of platter of multiple types or consumed along with meal slash 1 from above mentioned scores

2. Food item with added sugar or food belonging to miscellaneous food item consumed consecutively within 60 minutes interval then add 1 for the later score.

Table 3 One serving in house hold measurements for given food groups

\begin{tabular}{|l|l|}
\hline Food Group & One serving in house hold measurements \\
\hline Grains \& Cereals & $\begin{array}{l}1 \text { slice bread } \\
1 \text { medium sized chapathi, Dosa, Idli } \\
\square \text { cup cooked cereal, rice or pasta }\end{array}$ \\
\hline Vegetable & $\begin{array}{l}1 \text { cup chopped raw leafy vegetables } \\
\square \text { cup chopped other vegetables raw or cooked } \\
\square \text { cup vegetable juice }\end{array}$ \\
\hline Fruit & $\begin{array}{l}1 \text { medium apple, banana or orange } \\
\square \text { cup chopped fruit or canned fruit } \\
\square \text { cup fruitjuice }\end{array}$ \\
\hline Milk Yogurt and Cheese & 1 cup or $\square$ glass milk or Yogurt \\
$1 / 8^{\text {th }}$ cup cheese \\
$2 / 8^{\text {th }}$ cup cheese
\end{tabular}

Table 4 Average servings for individual food group serving for Children with moderate calorie level (2200 calories) given by FGP (2002) ${ }^{17}$

\begin{tabular}{|l|l|}
\hline Food Group & For 2200 calories \\
\hline Grain group servings & 9 \\
\hline Vegetable group servings & 4 \\
\hline Fruit group servings & 3 \\
\hline Milk group servings & 3 \\
\hline Meat group servings & 6 \\
\hline
\end{tabular}

Table 5 Mlustration for Diet diary analysis Day 


\begin{tabular}{|c|c|c|c|c|c|c|c|c|c|c|}
\hline \multicolumn{11}{|c|}{ Day 1} \\
\hline Time & Food & Quanti & OHR & Description & Score & Grain & Protein & Fruit & Milk & Vegetable \\
\hline $7.00 \mathrm{am}$ & Milk with Sugar & 1 Glas & & $\begin{array}{l}\text { Step } 1 \\
\text { Single type } \\
\text { Not a part of Miscellaneous } \\
\text { Step } 2 \\
\text { Processed, } \\
\text { Belongs to Milk group }=1.5 \\
\text { External sugar added }=1 \\
\text { Liquid }=0 \\
\text { Non sticky }=0\end{array}$ & 2.5 & & & & 2 & \\
\hline 8. $15 \mathrm{am}$ & Uppit \& kesari bath & $\begin{array}{r}1 \text { cup }+1 \\
\text { cup }\end{array}$ & $\mathrm{Y}$ & $\begin{array}{l}\text { Step } 1 \\
\text { Platter of multiple types } \\
\text { One food item is a Part of } \\
\text { Miscellaneous }=3.5\end{array}$ & 3.5 & 3 & & & & \\
\hline $9.30 \mathrm{am}$ & Chocolate & 1 & & $\begin{array}{l}\text { Step } 1 \\
\text { Single type } \\
\text { Part of Miscellaneous }=4.5\end{array}$ & 4.5 & 0 & & & & \\
\hline $10.15 \mathrm{am}$ & Cake & 2 & & $\begin{array}{l}\text { Step } 1 \\
\text { Singe type } \\
\text { Part of Miscellaneous=4.5 } \\
\text { Two Miscellaneous items } \\
\text { consumed within } 60 \text { min interval } \\
=1\end{array}$ & 5.5 & 2 & & & & \\
\hline $12.45 \mathrm{pm}$ & $\begin{array}{l}\text { Lunch -spiced rice } \\
\text { with chicken with } \\
\text { jamoon }\end{array}$ & $\begin{array}{c}1 \\
\text { Bowl }+1 \text { p }\end{array}$ & $\mathrm{Y}$ & $\begin{array}{l}\text { Platter of multiple types } \\
\text { One food item is a Part of } \\
\text { Miscellaneous }=3.5\end{array}$ & 3.5 & 4 & 1 & & & \\
\hline $6.00 \mathrm{pm}$ & Chats with Ice cream & $\begin{array}{r}1 \text { cup }+ \\
\text { scoop }\end{array}$ & & $\begin{array}{l}\text { Platter of multiple types } \\
\text { One food item is Part of } \\
\text { Miscellaneous=3.5 }\end{array}$ & 3.5 & & & & 1 & \\
\hline $8.00 \mathrm{pm}$ & $\begin{array}{l}\text { Dinner-Cheese } \\
\text { Vegetable Pizza and } \\
\text { Pasta }\end{array}$ & $\begin{array}{r}\text { 2slice } \\
\text { 1cup }\end{array}$ & $\mathrm{Y}$ & $\begin{array}{l}\text { Step } 1 \\
\text { Platter of multiple types } \\
\text { No food item is Part of } \\
\text { Miscellaneous } \\
\text { Step } 2 \\
\text { Processed } \\
\text { Major food item Pizza belongs to } \\
\text { grain group = } 1.5 \\
\text { External sugar not added }=0 \\
\text { Solid=1 } \\
\text { Sticky }=1\end{array}$ & 3.5 & 3 & & & 1 & 1 \\
\hline $8.30 \mathrm{pm}$ & Banana & 1 & & $\begin{array}{l}\text { Step } 1 \\
\text { Single type } \\
\text { Not Part of Miscellaneous } \\
\text { Step } 2 \\
\text { Natural } \\
\text { Fruit group }=0.5 \\
\text { Solid }=1 \\
\text { Non sticky }=0\end{array}$ & 1.5 & & & 1 & & \\
\hline \multicolumn{5}{|c|}{ Child is inconsistent in following the oral hygiene regime. } & 2 & & & & & \\
\hline \multicolumn{5}{|c|}{ Day 1 score } & 30 & 12 & 1 & 1 & 4 & 1 \\
\hline \multicolumn{11}{|c|}{ Day 2} \\
\hline Time & Food & Quantity & OHR & Description & Score & Grain & Protein & Fruit & Milk & Vegetable \\
\hline $7.00 \mathrm{am}$ & Milk with malt & 1 Glass & & $\begin{array}{l}\text { Step } 1 \\
\text { Singe type } \\
\text { Not a part of Miscellaneous } \\
\text { Step } 2 \\
\text { Processed } \\
\text { Belongs to Milk group }=1.5 \\
\text { External sugar added }=1 \\
\text { Liquid }=0 \\
\text { Non sticky }=0\end{array}$ & 2.5 & & & & 2 & \\
\hline $8.15 \mathrm{am}$ & Idli sambar & $\begin{array}{c}2 \text { pieces }+ \\
1 \text { cup }\end{array}$ & $\mathrm{Y}$ & $\begin{array}{l}\text { Step } 1 \\
\text { Singe type } \\
\text { Not a Part of Miscellaneous } \\
\text { Step } 2 \\
\text { Processed } \\
\text { Grain group }=1.5 \\
\text { External sugar not added }=0 \\
\text { Solid }=1 \\
\text { Non Sticky }=0\end{array}$ & 2.5 & 2 & 1 & & & 1 \\
\hline $9.30 \mathrm{am}$ & Dry fruits & 2 Table & & Step 1 & 2.5 & & & 1 & & \\
\hline
\end{tabular}

Page 12/19 


\begin{tabular}{|c|c|c|c|c|c|c|c|c|c|c|}
\hline & & spoon & & $\begin{array}{l}\text { Platter of multiple types } \\
\text { Not a Part of Miscellaneous } \\
\text { Step } 2 \\
\text { Processed } \\
\text { Fruit group }=1.5 \\
\text { External sugar not added }=0 \\
\text { Solid=1 } \\
\text { Sticky }=0\end{array}$ & & & & & & \\
\hline $10.15 \mathrm{am}$ & Jelly with cream & $\begin{array}{c}\text { 1slice }+1 \\
\text { scoop }\end{array}$ & & $\begin{array}{l}\text { Step } 1 \\
\text { Platter of multiple types } \\
\text { Both food item belonging to } \\
\text { Miscellaneous }=4.5\end{array}$ & 5 & & & & 1 & \\
\hline $12.45 \mathrm{pm}$ & $\begin{array}{l}\text { Lunch -rice and lentil } \\
\text { curry with salt lassi }\end{array}$ & $\begin{array}{l}1 \text { Bowl }+1 \\
\text { cup }+1 \text { cup }\end{array}$ & $\mathrm{Y}$ & $\begin{array}{l}\text { Step } 1 \\
\text { Platter of multiple types } \\
\text { Does not contain food item } \\
\text { belonging to Miscellaneous } \\
\text { Step } 2 \\
\text { Processed } \\
\text { Grain group= } 1.5 \\
\text { External sugar not added =0 } \\
\text { Solid=1 } \\
\text { Non Sticky=0 }\end{array}$ & 2.5 & 4 & 1 & & 1 & 1 \\
\hline $6.00 \mathrm{pm}$ & Sweet milk $\&$ biscuit & 1glass +2 & & $\begin{array}{l}\text { Step } 1 \\
\text { Platter of multiple types } \\
\text { One food item is a Part of } \\
\text { Miscellaneous }=3.5\end{array}$ & 3.5 & 1 & & & 2 & \\
\hline $8.00 \mathrm{pm}$ & $\begin{array}{l}\text { Dinner- Panner stuffed } \\
\text { chapati rolls }\end{array}$ & 2 & $\mathrm{Y}$ & $\begin{array}{l}\text { Step } 1 \\
\text { Platter of multiple types } \\
\text { Does not contain food item } \\
\text { belonging to Miscellaneous } \\
\text { Step } 2 \\
\text { Processed } \\
\text { Grain group= } 1.5 \\
\text { External sugar not added =0 } \\
\text { Solid=1 } \\
\text { Non Sticky=0 }\end{array}$ & 2.5 & 2 & & & 1 & \\
\hline $8.30 \mathrm{pm}$ & Chocolava cake & 1 & & $\begin{array}{l}\text { Step } 1 \\
\text { Singe type, } \\
\text { Part of Miscellaneous=4.5 }\end{array}$ & 4.5 & 1 & & & & \\
\hline \multicolumn{5}{|c|}{$\begin{array}{l}\text { Child is inconsistent in following the oral hygiene regime. } \\
\text { child has consumed food item with added sugar just before bed and skipeds oral hygiene regime }\end{array}$} & $\begin{array}{l}2 \\
2\end{array}$ & & & & & \\
\hline \multicolumn{5}{|c|}{ Day 2 score } & 29.5 & 10 & 2 & 1 & 7 & 2 \\
\hline \multicolumn{11}{|c|}{ Day 3} \\
\hline Time & Food & Quantity & OHR & Description & Score & Grain & Protein & Fruit & Milk & Vegetable \\
\hline 7.00am & $\begin{array}{l}\text { Milk with } \\
\text { malt }\end{array}$ & 1 Glass & & $\begin{array}{l}\text { Step } 1 \\
\text { Single type } \\
\text { Not a part of Miscellaneous } \\
\text { Step } 2 \\
\text { Processed, } \\
\text { Belongs to Milk group }=1.5 \\
\text { External sugar added }=1 \\
\text { Liquid }=0 \\
\text { Non sticky }=0\end{array}$ & 2.5 & & & & 2 & \\
\hline $8.15 \mathrm{am}$ & $\begin{array}{l}\text { Aloo paratha } \\
\text { with butter }\end{array}$ & $\begin{array}{l}1+2 \text { table } \\
\text { spoon }\end{array}$ & $\mathrm{Y}$ & $\begin{array}{l}\text { Step } 1 \\
\text { Platter of multiple types, } \\
\text { Does not contain food item } \\
\text { belonging to Miscellaneous } \\
\text { Step } 2 \\
\text { Processed } \\
\text { Grain group= } 1.5 \\
\text { External sugar not added =0 } \\
\text { Solid=1 } \\
\text { Non Sticky }=0\end{array}$ & 2.5 & 1 & & & 1 & 1 \\
\hline $9.30 \mathrm{am}$ & Chips & 1 pack & & $\begin{array}{l}\text { Step } 1 \\
\text { Singe type, Processed } \\
\text { Part of Miscellaneous }=4.5\end{array}$ & 4.5 & & & & & 1 \\
\hline $10.15 \mathrm{am}$ & Coke & $1-200 \mathrm{ml}$ & & $\begin{array}{l}\text { Step } 1 \\
\text { Singe type } \\
\text { Part of Miscellaneous }=4.5 \\
\text { Two Miscellaneous items } \\
\text { consumed within } 60 \mathrm{~min} \\
\text { interval =1 } \\
\end{array}$ & 5.5 & & & & & \\
\hline $12.45 \mathrm{am}$ & Lunch-chapati & $2+1$ cup +1 & $\mathrm{Y}$ & Step 1 & 2.5 & 2 & & 2 & & 2 \\
\hline
\end{tabular}

Page 13/19 


\begin{tabular}{|c|c|c|c|c|c|c|c|c|c|c|}
\hline & $\begin{array}{c}\text { with } \\
\text { vegetables } \\
\text { and fruits }\end{array}$ & cup & & $\begin{array}{l}\text { Platter of multiple types } \\
\text { Does not contain food item } \\
\text { belonging to Miscellaneous } \\
\text { Step } 2 \\
\text { Processed } \\
\text { Grain group }=1.5 \\
\text { External sugar not added }=0 \\
\text { Solid=1 } \\
\text { Non Sticky }=0\end{array}$ & & & & & & \\
\hline $6.00 \mathrm{am}$ & $\begin{array}{l}\text { Vegetable } \\
\text { sandwich }\end{array}$ & 2 & $\mathrm{Y}$ & $\begin{array}{l}\text { Step } 1 \\
\text { Single types } \\
\text { Does not contain food item } \\
\text { belonging to Miscellaneous } \\
\text { Step } 2 \\
\text { Processed } \\
\text { Grain group }=1.5 \\
\text { External sugar not added }=0 \\
\text { Solid }=1 \\
\text { Non Sticky }=0\end{array}$ & 2.5 & 2 & & & & 1 \\
\hline $8.00 \mathrm{am}$ & $\begin{array}{l}\text { Dinner- Rice } \\
\text { with lentil } \\
\text { curry }\end{array}$ & $\begin{array}{l}1 \text { bowl } \\
+1 \text { cup }\end{array}$ & & $\begin{array}{l}\text { Step } 1 \\
\text { Platter of multiple types } \\
\text { Does not contain food item } \\
\text { belonging to Miscellaneous } \\
\text { Step } 2 \\
\text { Processed } \\
\text { Grain group }=1.5 \\
\text { External sugar not added }=0 \\
\text { Solid }=1 \\
\text { Non Sticky }=0\end{array}$ & 2.5 & 4 & 1 & & & 1 \\
\hline $8.30 \mathrm{am}$ & Banana & 1 & $\mathrm{Y}$ & $\begin{array}{l}\text { Step } 1 \\
\text { Single type } \\
\text { Not Part of Miscellaneous } \\
\text { Step } 2 \\
\text { Natural } \\
\text { Fruit group }=0.5 \\
\text { Solid=1 } \\
\text { Non sticky }=0\end{array}$ & 0.5 & & & 1 & & \\
\hline \multicolumn{5}{|c|}{ Child is inconsistent in following the oral hygiene regime. } & 2 & & & & & \\
\hline \multicolumn{5}{|l|}{ Day 3 score } & 25 & 9 & 1 & 3 & 3 & 6 \\
\hline
\end{tabular}

\begin{tabular}{|c|c|c|c|c|c|c|c|c|c|c|}
\hline Time & Food & OHR & Quantity & & Score & Grain & Protein & Fruit & Milk & Vegetable \\
\hline $7.00 \mathrm{am}$ & Badam milk & & 1 Glass & $\begin{array}{l}\text { Step 1 } \\
\text { Single type } \\
\text { Not a part of } \\
\text { Miscellaneous } \\
\text { Step 2 } \\
\text { Processed, } \\
\text { Belongs to Milk } \\
\text { group }=1.5 \\
\text { External sugar added } \\
=1 \\
\text { Liquid }=0 \\
\text { Non sticky }=0\end{array}$ & 3 & & & & 2 & \\
\hline 8. $15 \mathrm{am}$ & Idli sambar & $\mathrm{Y}$ & $\begin{array}{l}2 \text { pieces }+1 \\
\text { cup }\end{array}$ & $\begin{array}{l}\text { Step 1 } \\
\text { Singe type } \\
\text { Not a Part of } \\
\text { Miscellaneous } \\
\text { Step } 2 \\
\text { Processed } \\
\text { Grain group }=1.5 \\
\text { External sugar not } \\
\text { added }=0 \\
\text { Solid }=1 \\
\text { Non Sticky }=0\end{array}$ & 2.5 & 2 & 1 & & & 1 \\
\hline $9.30 \mathrm{am}$ & Fruit juice & & 1Glass & $\begin{array}{l}\text { Step 1 } \\
\text { Single type } \\
\text { Not Part of } \\
\text { Miscellaneous } \\
\text { Step } 2 \\
\text { Processed } \\
\text { Fruit group }=1.5 \\
\text { External sugar added } \\
=1 \\
\text { Liquid }=0 \\
\text { Non sticky }=0\end{array}$ & 2.5 & & & 2 & & \\
\hline
\end{tabular}

Page 14/19 


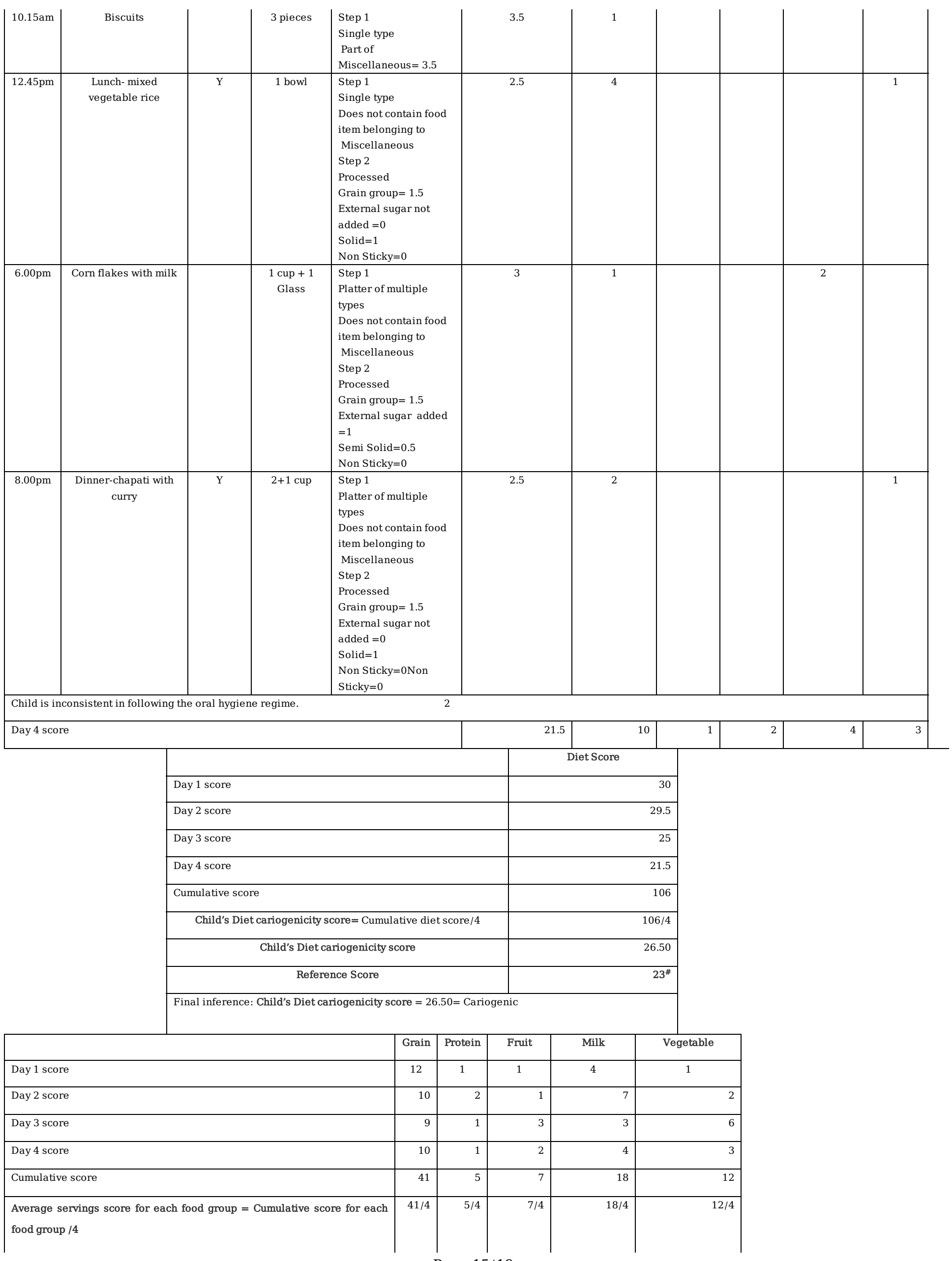




\begin{tabular}{|c|c|c|c|c|c|}
\hline Average servings score for each food group & 10.20 & 1.25 & 1.75 & 4.50 & 3.00 \\
\hline Reference Score & 9* & 6* & 3* & 3* & 4* \\
\hline \multicolumn{6}{|c|}{ Average servings scores of protein, fruit and vegetable is less than reference $=$ Non health full diet } \\
\hline \multicolumn{6}{|c|}{ Classification of child, diet= Category $I V$ - Cariogenic, Non- health full } \\
\hline
\end{tabular}

\#As per ROC curve derived from present study on Indian children,

*Indicated serving by FGP for moderate calorie level (2200 cal)

\$\$ Even one of the five food groups do not fulfill the reference scores consider the diet as non-healthful

Table 6 Ilustration for post diet counselling modifications suggested

\begin{tabular}{|c|c|c|c|c|c|c|c|c|c|c|c|c|}
\hline \multicolumn{13}{|c|}{ Day 1} \\
\hline \multirow[t]{2}{*}{ Time } & \multirow[t]{2}{*}{ Food } & \multirow[t]{2}{*}{ Quantity } & \multirow[t]{2}{*}{ OHR } & \multirow[t]{2}{*}{ Diet counseling } & \multicolumn{2}{|l|}{ Score } & \multirow[t]{2}{*}{ Grain } & \multirow[t]{2}{*}{ Protein } & \multirow[t]{2}{*}{ Fruit } & \multirow[t]{2}{*}{ Milk } & \multirow{2}{*}{\multicolumn{2}{|c|}{ Vegetable }} \\
\hline & & & & & Before & After & & & & & & \\
\hline $7.00 \mathrm{am}$ & Milk with Sugar & 1 Glass & & Advised oral hygiene regime & 2.5 & 2.5 & & & & 2 & & \\
\hline 8. $15 \mathrm{am}$ & Uppit \& kesari bath & $\begin{array}{l}1 \operatorname{cup}+1 / 2 \\
\operatorname{cup}\end{array}$ & $\mathrm{Y}$ & Advised to eat 1 egg & 3.5 & 3.5 & $3+2$ & 1 & & & & \\
\hline $9.30 \mathrm{am}$ & Chocolate & 1 & & $\begin{array}{l}\text { Advised to combine with breakfast } \\
\text { and oral hygiene regime }\end{array}$ & 4.5 & 0 & 0 & & & & & \\
\hline $10.15 \mathrm{am}$ & Cake & 2 & & $\begin{array}{l}\text { Advised to combine with breakfast } \\
\text { and oral hygiene regime } \\
\text { Instead of cake Advised to eat } 1 \text { cup sliced } \\
\text { raw vegetables }\end{array}$ & 5.5 & 0 & $\begin{array}{l}\text { Shifted to } \\
\text { breakfast }\end{array}$ & & & & & 2 \\
\hline $12.45 \mathrm{pm}$ & $\begin{array}{l}\text { Lunch -spiced rice with chicken } \\
\text { with jamoon }\end{array}$ & $\begin{array}{c}1 \\
\text { Bowl }+1 \text { piece }\end{array}$ & $\mathrm{Y}$ & $\begin{array}{l}\text { Advised oral hygiene regime } \\
\text { Advised to eat } 1 \text { cup sprouts and } 1 / 2 \text { cup } \\
\text { vegetable }\end{array}$ & 3.5 & 3.5 & 4 & $1+2$ & & & & 1 \\
\hline $6.00 \mathrm{pm}$ & Chats with Ice cream & $\begin{array}{c}1 \mathrm{cup}+1 \\
\text { scoop }\end{array}$ & & $\begin{array}{l}\text { Advised oral hygiene regime } \\
\text { Advised to eat 1cup fruit }\end{array}$ & 3.5 & 3.5 & & & 2 & 1 & & \\
\hline $8.00 \mathrm{pm}$ & $\begin{array}{l}\text { Dinner-Cheese } \\
\text { Vegetable Pizza and } \\
\text { Pasta }\end{array}$ & $\begin{array}{l}2 \text { slice }+ \\
1 \text { cup }\end{array}$ & $\mathrm{Y}$ & $\begin{array}{l}\text { Advised oral hygiene regime } \\
\text { Advised to eat 1cup cooked bean }\end{array}$ & 3.5 & 3.5 & 3 & 2 & & 1 & & 1 \\
\hline $8.30 \mathrm{pm}$ & Banana & 1 & & Advised oral hygiene regime & 1.5 & 1.5 & & & 1 & & & \\
\hline \multicolumn{5}{|c|}{ Child is inconsistent in following the oral hygiene regime. } & 2 & \multicolumn{2}{|c|}{0} & & & & & \\
\hline \multicolumn{5}{|c|}{ Day 1 score } & 30 & \multicolumn{2}{|c|}{16} & & & & & \\
\hline & & & & & & \multicolumn{2}{|c|}{ Before } & 12 & & 1 & 4 & 1 \\
\hline & & & & & & \multicolumn{2}{|c|}{ After } & 12 & & 3 & 4 & 4 \\
\hline
\end{tabular}

Table 7 Mean DMFT, deft values low and high caries severity groups

\begin{tabular}{|c|c|c|c|c|c|c|c|}
\hline & Caries Severity & $\mathbf{N}$ & Mean & Std. Deviation & Mean Difference & F & $\mathbf{p}$ \\
\hline \multirow[t]{2}{*}{ DMFT } & Low & 388 & 0.0309 & 0.17335 & \multirow[t]{2}{*}{-0.63228} & \multirow{2}{*}{\multicolumn{2}{|c|}{520.480 .001}} \\
\hline & High & 386 & 0.6632 & 1.18236 & & & \\
\hline \multirow[t]{2}{*}{ deft } & Low & 388 & 0.2191 & 0.41415 & \multirow[t]{2}{*}{-2.94932} & \multirow{2}{*}{\multicolumn{2}{|c|}{415.3250 .001}} \\
\hline & High & 386 & 3.1684 & 1.95139 & & & \\
\hline \multirow[t]{2}{*}{ DMFT+deft } & Low & 388 & 0.25 & 0.43357 & \multirow[t]{2}{*}{-3.58161} & \multirow{2}{*}{\multicolumn{2}{|c|}{338.3310 .001}} \\
\hline & High & 386 & 3.8316 & 1.74925 & & & \\
\hline
\end{tabular}

Table 8 Sensitivity and 1 - specificity for diet cariogenic score at various dental caries cut-off points in children 


\begin{tabular}{|c|c|c|c|c|}
\hline Diet cariogenic score & & Sensitivity & 1 - Specificity & \\
\hline 14.0000 & & 1 & 1 & \\
\hline 15.5000 & & 0.972 & 0.894 & \\
\hline 16.5000 & & 0.93 & 0.621 & \\
\hline 17.5000 & & 0.907 & 0.451 & \\
\hline 18.5000 & & 0.899 & 0.291 & \\
\hline 19.5000 & & 0.894 & 0.186 & \\
\hline 20.5000 & & 0.894 & 0.175 & \\
\hline 21.5000 & & 0.85 & 0.119 & \\
\hline 22.5000 & & 0.707 & 0.095 & \\
\hline 23.5000 & & 0.637 & 0.082 & \\
\hline 24.5000 & & 0.456 & 0.062 & \\
\hline 25.5000 & & 0.422 & 0.059 & \\
\hline 26.5000 & & 0.386 & 0.054 & \\
\hline 27.5000 & & 0.352 & 0.052 & \\
\hline 28.5000 & & 0.319 & 0.046 & \\
\hline 30.5000 & & 0.285 & 0.041 & \\
\hline 32.5000 & & 0.249 & 0.036 & \\
\hline 33.5000 & & 0.14 & 0.021 & \\
\hline 34.5000 & & 0.07 & 0.01 & \\
\hline 36.0000 & & 0.036 & 0.005 & \\
\hline 38.0000 & & 0 & 0 & \\
\hline Caries & $\mathrm{N}$ & Area & Std. Error ${ }^{\mathrm{a}}$ & Asymptotic Sig. ${ }^{\mathrm{b}}$ \\
\hline Positive & 386 & 0.869 & 0.014 & 0.001 \\
\hline Negative & 388 & & & \\
\hline
\end{tabular}

Figures

Food item

Single type

Check if it is a part of Miscellaneous

Yes

No

\section{Proceed to step 2}

Platter of multiple types
Assign score

Refer Table 2
Yes

Assign single score of 3.5 for entire platter of multiple types

Check if it contains any food items belonging to Miscellaneous

Identify major one food item
and proceed to step 2

Figure 1

Analysis of diet diary for assessment of cariogenicity-Step 1 
Natural

Identify the food group it belongs and assign score

\begin{tabular}{|ll|}
\hline Water & 0 \\
Vegetable & 0 \\
Legumes \& Pulses & 0 \\
Meat Fish Poultry \& Egg & 0 \\
Fat and oils & 0 \\
Milk and Milk product & 0.5 \\
Grains \& Cereals & 0.5 \\
Fruits & 0.5 \\
\hline
\end{tabular}

Identify its physical form
Recognize the major ingredient of the food and classify its food group to assign score

$\begin{array}{ll}\text { Water } & 0 \\ \text { Vegetable } & 0 \\ \text { Legumes \& Pulses } & 0 \\ \text { Meat Fish Poultry \& Egg } & 0 \\ \text { Fat and oils } & 0 \\ \text { Milk and Milk product } & 1.5 \\ \text { Grains \& Cereals } & 1.5 \\ \text { Fruits } & 1.5\end{array}$

Solid (Add 1)

Semi Solid (Add 0.5)
Liquid (Add 0)
With addition of External sugar (Add 1)
Without addition of External sugar (Add 0)

Sticky (Add 1)

Non-sticky (Add 0)

Identify its physical form

Child after every intake does not follow or is inconsistent in following the oral hygiene regime then add a score of 2 to per day diet score. If the child consumes food item with added sugar just before bed and skips oral hygiene regime add another score of 2 to per day diet score.

\section{Figure 2}

Analysis of diet diary for assessment of cariogenicity- Step 2 


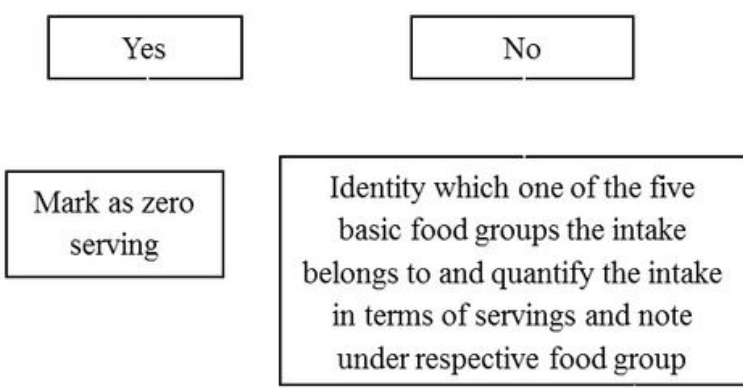

Mark zero serving for miscellaneous food items

\section{Grains \& Cereals \\ Vegetable \\ Fruit \\ Milk Yogurt and Cheese \\ Meat Poultry Fish}

\section{Figure 3}

Analysis of diet diary for its health-fullness

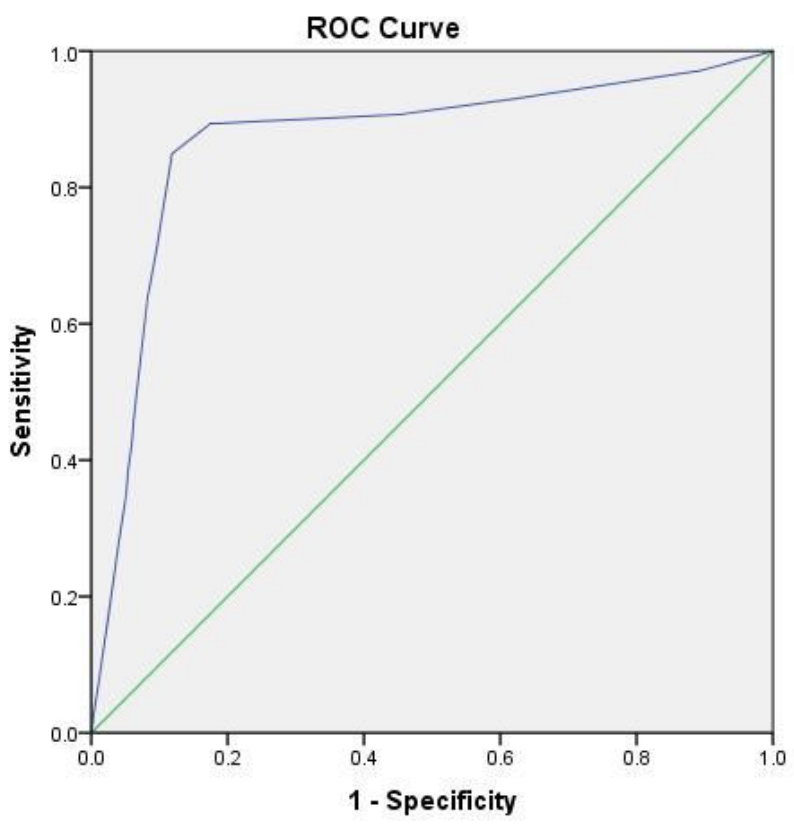

Diagonal segments are produced by ties.

\section{Figure 4}

Receiver operating characteristic curve comparing Dental caries and Diet cariogenic score for children 